\title{
Health effects following long-term exposure to thorium dusts: a twenty-year follow-up study in China*
}

\author{
X.A. $\mathrm{CHEN}^{1}$, Y.E. $\mathrm{CHENG}^{1}$, H. XIAO ${ }^{1}$, G. FENG ${ }^{2}$, Y.H. DENG ${ }^{2}$, \\ Z.L. $\mathrm{FENG}^{2}$, L. $\mathrm{CHEN}^{1}$, X.M. HAN ${ }^{2}$, Y.J. YANG ${ }^{1}$, Z.H. DONG ${ }^{1}$ \\ and R. ZHENG ${ }^{1}$
}

(Manuscript received 18 June 2003, accepted 25 June 2004)

ABSTRACT A twenty-year follow-up study was carried out at Baiyun Obo Rare-earth Iron Mine in China, This mine has been mined since 1958. Its ore contains $0.04 \%$ of $\mathrm{ThO}_{2}$ and $10 \%$ of $\mathrm{SiO}_{2}$. The purpose of this study is to investigate possible health effects in dust-exposed miners following long-term exposure to thorium-containing dusts and thoron progeny. By using the negative high voltage exhaled thoron progeny measurement system to estimate the miner's thorium lung burden. The highest thorium lung burden among 1158 measurements of 638 miners was $11.11 \mathrm{~Bq}$. The incidence of stage $0^{+}$pneumoconiosis was increased among dust-exposed miners. An epidemiological study showed that the lung cancer mortality of the dust-exposed miners was significantly $(\mathbf{p}<\mathbf{0 . 0 0 5})$ higher than that of the non-exposed group. It is suggested that the difference results in the long-term exposure to thorium-containing dusts (carcinogens are $\mathrm{ThO}_{2}$ and $\mathrm{SiO}_{2}$ ) and thoron progeny. This is the first evidence in humans of the carcinogenicity after long-term inhalation of thorium-containing dusts and thoron progeny. The total person-years of observation for the dustexposed miners and the controls were 62712 and 34672 respectively.

RÉSUMÉ Effets sanitaires après une exposition prolongée à des poussières de thorium : une étude sur un suivi de 20 ans en Chine.

Une étude de suivi sanitaire a été effectuée à la mine de terres rares de Baiyun Obo en Chine. Cette mine est en activité depuis 1958. Son minerai contient $0,04 \%$ de $\mathrm{ThO}_{2}$ et $10 \%$ de $\mathrm{SiO}_{2}$. Le but de cette étude est d'étudier les possibles effets sur la santé des mineurs exposés pendant une longue période aux poussières contenant du thorium et des descendants du thoron. La charge coniotique en thorium a été évaluée par une méthode électrique de mesure du thoron exhalé. La charge pulmonaire la plus élevée en thorium parmi les 1158 mesures effectuées sur 638 mineurs était de $11,11 \mathrm{~Bq}$. L'incidence du stade $0^{+}$de la pneumoconiose était augmentée parmi les mineurs exposés. Une étude épidémiologique montre que la mortalité liée au cancer pulmonaire des mineurs exposés est significativement $(p<0,005)$ plus élevée que dans groupe non-exposé. Il est suggéré que cette différence résulte de l'exposition à long terme aux poussières contenant du thorium (les agents cancérogènes sont $\mathrm{ThO}_{2}$ et $\mathrm{SiO}_{2}$ ) et aux descendants du thoron. Cette observation est la première montrant

\footnotetext{
A project from National Natural Science Foundation of China. Project no. 3860285 (1987.1-1992.12), a project from IAEA. Project no. 7715/RB (1993.12.15-1994.12.15), a project from IAEA Project no. 11526 RBF (2000.12.15-2001.12.15). 1 National Institute for Radiological Protection, Chinese Center for Disease Control and Prevention, P.O. Box 8018, Beijing 100088 , P.R. China.

2 Hospital of Baiyun Obo Rare-earth Iron Mine Baiyun Obo, Baotou 014080, P.R. China.
} 


\section{Introduction}

Baiyan Obo Rare-earth Co-existence Iron Mine is one of the largest rare earth mine in the world. It has been mined since 1958. Its ore contains not only iron, rare-earth elements and silica dioxide but also thorium at a concentration of $0.04 \% . \mathrm{SiO}_{2}$ is at a concentration of $10 \%$. Air concentrations of thorium-containing dusts in working place are quite high. For example, in the crushing workshop, air concentration is in the range $9.30-875.0 \mathrm{mg} . \mathrm{m}^{-3}$, with an average of $188.7 \mathrm{mg} \cdot \mathrm{m}^{-3}$. Equivalent value of thorium activity concentration in air is in the range $0.015-1.41 \mathrm{~Bq} \cdot \mathrm{m}^{-3}$, with an average of 0.30 Bq. $\mathrm{m}^{-3}$. The average AMAD value of 10 dust samples from both crushing workshop and mining workshop was at a value of $6.0 \pm 2.2 \mu \mathrm{m}$. (in the range from 4.7-12.7 $\mu \mathrm{m}$ ) (Li Wenyuan et al., 1988). The potential alpha energy concentrations of thoron short-lived daughters in the crushing working area are in the range $4.20 \times 10^{2}-6.77 \times 10^{4} \mathrm{MeV} . \mathrm{L}^{-1}$, with an average of $1.08 \times$ $10^{4} \mathrm{MeV} . \mathrm{L}^{-1}$, It is higher than that of short-lived radon daughters by a factor of about 10 . High gamma-ray exposures only appeared in mining workshops. The highest value was $2.31 \mu \mathrm{Gy} \cdot \mathrm{h}^{-1}$.

Since 1982, the relationship between thorium lung burden and health effects on miners has been investigated in this mine. The total number of miners and staff members in this mine in 2001 was 6 983. Among them, 3016 miners were exposed to this dust and 3967 miners and staff members were not exposed.

\section{Methods}

The method used to measure exhaled thoron activity was developed in 1982 from the experience of Argonne National Laboratory in the USA (Porstendorfer and Mercer, 1979). It is based on electrostatic collection onto a negatively charged Mylar disc of the thoron daughter ${ }^{212} \mathrm{~Pb} 85-88 \%$ of which is positively charged. The exhaled thoron activity is expressed as the activity of the freely emanating ${ }^{224} \mathrm{Ra}$ (the parent of ${ }^{220} \mathrm{Rn}$ ) that would support concentration measured at the subject's mouth. A conversion factor of $3.7 \mathrm{~Bq}$ emanating ${ }^{224} \mathrm{Ra}$ equivalent activity at the mouth to $37 \mathrm{~Bq}$ of ${ }^{232} \mathrm{Th}$ was used to estimate the thorium lung burden (Stehney et al., 1980). The counter background is extremely low (6 counts. $\left.\mathrm{d}^{-1}\right)$. The overall uncertainty is strongly dependent on the emanating ${ }^{224} \mathrm{Ra}$ and ranges from \pm 0.013 to $\pm 0.07 \mathrm{~Bq}$ as the emanating ${ }^{224} \mathrm{Ra}$ ranges from $0.037 \mathrm{~Bq}$ to $3.70 \mathrm{~Bq}$ (Tab. I). 
TABLE I

The basic performance of the electrostatic measurement system. Performances de base du système de mesure électrostatique.

\begin{tabular}{lc}
\hline Item & Value \\
\hline Counter background $\left(\right.$ counts. $\left.\min ^{-1}\right)$ & 0.003 \\
$\begin{array}{l}\text { Minimum detection limit of thoron outside the body }(\mathrm{Bq}) \\
\text { (zero activity } \pm 3 \sigma)\end{array}$ & 0.007 \\
$\begin{array}{l}\text { Lower limit for the detection of thorium contamination in } \\
\text { the miners'lungs }(\mathrm{Bq})\left({ }^{224} \mathrm{Ra} \text { at the mouth) }\right.\end{array}$ & 0.068 \\
$\begin{array}{l}\text { Overall uncertainty depends on the value of the emanating } \\
{ }^{224} \mathrm{Ra} \text { at the mouth }(\mathrm{Bq})\end{array}$ & $0.037-3.7$ \\
Median coefficient of variation $(\%)$ & $\pm 0.013-0.070)$ \\
\hline
\end{tabular}

A total of 1301 measurements of exhaled thoron activity were carried out on 781 individuals during the period 1983-1994. Of these, 1158 measurements were performed on 638 thorium miners, and 143 measurements were made on 143 unexposed workers (controls). In addition, during this period, 1158 medical examinations were performed on these same 638 dust-exposed miners (Chen et al., 2000). An epidemiological study on the mortality rates of lung cancers in the dustexposed miners and dust-unexposed miners was carried out in 2001 (Chen, 2001).

\section{Results}

\subsection{Thorium lung burden estimates of the dust-exposed miners and of the dust-unexposed miners}

The average value of thorium lung burden estimates for the 1158 measurements of 638 dust-exposed miners was $1.60 \mathrm{~Bq}$, while the average value of thorium lung burden estimates of 143 dust-unexposed miners was $0.30 \mathrm{~Bq}$. Of the 638 exposed miners for whom measurements were performed in the period from 1983 to 1994 , $585(91.7 \%)$ had a thorium lung burden less than $2.22 \mathrm{~Bq}$ (1 investigation level, see ICRP, 1968). The highest value determined here consisted of a thorium lung burden of $11.11 \mathrm{~Bq}$, which is one tenth of the permissible thorium lung burden (Tab. II) indicated in ICRP publication 10A (1975).

\subsection{Estimated thorium lung burdens and relationship to radiography of the dust-exposed mines (Chen et al., 2000)}

Our results showed that there would be a likely threshold of inhaled thorium containing dusts for inducing stage $0^{+}$pneumoconiosis (only fibrosis but no 


\section{TABLE II}

Summary of values for thorium lung burden estimates performed on miners (638 subjects). Résumé des charges pulmonaires en thorium, estimées parmi 638 mineurs.

\begin{tabular}{lc}
\hline Thorium lung burden estimates $(\mathbf{B q})$ & Number of subjects \\
\hline 11.11 & 1 \\
$8.89 \sim 11.07$ & 5 \\
$6.67 \sim 8.85$ & 2 \\
$4.44 \sim 6.63$ & 2 \\
$2.22 * \sim 4.41$ & 43 \\
$<2.19$ & 585 \\
\hline
\end{tabular}

TABLE III

Likely threshold for lung burden from thorium-containing dusts in the induction of stage $0^{+}$ pneumoconiosis.

Valeur probable du seuil de charge pulmonaire en thorium nécessaire pour entraîner une pneumoconiose de stade $0^{+}$.

\begin{tabular}{lccccc}
\hline \multirow{2}{*}{ Workshop } & \multirow{2}{*}{ Miners } & Cases & Thorium $(\mathbf{B q})$ & \multicolumn{2}{c}{ Likely threshold } \\
\cline { 5 - 6 } & & 8 & & for dust $(\mathbf{m g})$ & Year \\
\hline Crushing & 31 & 26 & 1.52 & $940^{*}$ & 1984 \\
Crushing & 94 & 4 & 1.26 & 803 & 1987 \\
Mining & 86 & 12 & 1.22 & 780 & 1988 \\
Crushing & 64 & 756 & 1994 \\
\hline * The data in this figure were derived as follows: 1 mg natural thorium $=4.037 \mathrm{~Bq} ; 1.52$ Bq thorium $=0.377$ mg. A
\end{tabular}
concentration of thorium of $0.377 \mathrm{mg} \times 2500$ (the percentage of thorium in the dusts is $0.04 \%$ ) $=941 \mathrm{mg}$ of dusts.

nodules apparent on the X-ray film). $0^{+}$is a stage between stage 0 , (normal), and stage 1 (pneumoconiosis).

The likely threshold is the lowest value of thorium and dust lung burden of the miners suffering from pneumoconiosis stage $0^{+}$(Tab. III).

\subsection{Lung cancer mortality among dust-exposed miners and dust-unexposed miners (Chen, 2001)}

An epidemiology study on lung cancer mortality of the dust-exposed miners and dust-unexposed miners (controls) was performed in 2001. The main results are listed in Table IV.

Table IV showed that the SMR of the dust-exposed miners and of the dustunexposed miners were greater than 1 . The SMR of the dust-exposed miners was 
TABLE IV

Standard mortality ratios (SMRs) of lung cancers (1977-March 2001).

Taux de mortalité standardisé (SMRs) de cancers pulmonaires (1977-mars 2001).

\begin{tabular}{lcccc}
\hline Group & Expected & Observed & SMR & 95\% Limits \\
\hline Dust-exposed miners & 4.406 & 27 & 6.13 & $4.41-8.52$ \\
Controls & 4.201 & 8 & 1.90 & $0.94-3.84$ \\
\hline
\end{tabular}

TABLE V

Standard mortality ratios (SMRs) of lung cancers (1977-December 1993).

Taux de mortalité standardisé (SMRs) de cancers pulmonaires (1997-décembre 1993).

\begin{tabular}{lcccc}
\hline Group & Expected & Observed & SMR & 95\% Limits \\
\hline Dust-exposed miners & 3.301 & 17 & 5.15 & $3.36-7.89$ \\
Controls & 3.480 & 8 & 2.30 & $1.17-4.51$ \\
\hline
\end{tabular}

much higher than that of the controls. The probability that 27 or more lung cancers would occur in the dust-exposed group, given the expected numbers and that a total of 35 occurred, is 0.0015 (Ginevan, 1981). The high SMR for lung cancers among dust exposed miners likely resulted from the inhaled thorium-containing dusts (carcinogens are $\mathrm{ThO}_{2}$ and $\mathrm{SiO}_{2}$ ) and its short-lived thoron progeny. The total person-years of observation of the dust exposed miners and the unexposed miners were 62712 and 34672 respectively.

Since 1994, 36 years after the initial operation of this mine, 10 additional lung cancers have appeared in dust-exposed miners. The probability that all ten of these would appear in the dust-exposed group, given the expectations in both groups during only this recent period, is 0.0066 .

Table V shows that even before 1994 the SMRs for both the dust-exposed and dust unexposed miners were greater than 1 . The SMR for the dust-exposed miners was more than that for the controls, and the probability that 17 or more lung cancers would occur among the dust-exposed miners given the expectations in both groups and that 25 total lung cancers appeared was marginally significant $(\mathrm{p}=0.04)($ Ginevan, 1981).

Using the LUDEP (Jarvis et al., 1996) implementation ICRP publication 66 (1994) lung model it may be estimated that long term (tens of years) inhalation of thorium-232, assuming an activity median aerodynamic diameter of $5 \mu \mathrm{m}$ and class $\mathrm{S}$ solubility behavior, results in an accumulated lung burden of $0.16 \mathrm{~Bq}$ per $\mathrm{Bq}_{\mathrm{y}} \mathrm{y}^{-1}$ of intake. We may therefore interpret the lung burden $1.6 \mathrm{~Bq}$ and reflecting a constant chronic inhalation intake of about $10 \mathrm{~Bq} \cdot \mathrm{y}^{-1}$. If we assume that the inhaled dust contains ${ }^{232} \mathrm{Th},{ }^{228} \mathrm{Ra},{ }^{228} \mathrm{Ac},{ }^{228} \mathrm{Th}$ and ${ }^{224} \mathrm{Ra}$ secular equilibrium, 
an intake of 10 Bq. $\mathrm{y}^{-1}$ corresponds to a committed equivalent dose to lung of $3.1 \times 10^{-3} \mathrm{~Sv}^{-y^{-1}}(10)$, and the average exposure time of 32 years for the dust exposed miners indicates an average individual cumulative committed equivalent dose to lung of $9.9 \times 10^{-2} \mathrm{~Sv}$.

If we take a risk coefficient for lung cancer of 1.6 per $10^{4}$ person years per $\mathrm{Sv}$, based on the Hiroshima and Nagasaki Life Span Study, the 62712 person years of follow-up for the dust exposed miners, together with the an average individual cumulative committed equivalent dose to lung of $9.9 \times 10^{-2} \mathrm{~Sv}$, would lead to an expectation of 0.99 case $(\sim 1.0$ case $)$.

According to Dr. Xu's (Xu Jinkui et al., 1994) investigation, the average annual exposure from thoron progeny is 1.84 WLM. Using the conversion factor from ICRP publication 47 (1986), the highest excess lung cancer due to 62712 person years is 2.06 cases.

In addition, we may consider that the 8 cases of lung cancer deaths in the control group were induced only from cigarette smoking, because the miners in the control group didn't expose to the thorium dusts. Therefore, we may also consider that among the 27 cases of lung cancer deaths in the dust exposed miners, there were at least 8 cases were due to the cigarette smoking, However, the person-years of the dust-exposed miners were higher than that of the person-years of the miners in control group by a factor of 1.48. Thus, the number of lung cancer deaths among the dust-exposed miners induced by cigarette smoking should be at a value of 12 cases.

In 1996, IARC monographs volume 68 (IARC, 1996) reported that there is sufficient evidence in humans for the carcinogenecity of inhaled crystalline silica in the form of quartz or cristobolite from occupational sources.

As already mentioned above the contents of $\mathrm{SiO}_{2}$ in the dust is much higher than that of the $\mathrm{ThO}_{2}(10 \%$ vs. $0.04 \%)$. So, there is enough reason to consider $\mathrm{SiO}_{2}$ is one of the most important factors in inducing the excess lung cancer deaths among the dust-exposed miners in this mine.

According to the above-mentioned estimation, among the 27 cases of lung cancer deaths of the dust exposed miners, 1 case was induced by the inhaled thorium; 2.0 cases were induced by the inhaled short-lived thoron daughters, 12 cases were induced by cigarette smoking and then the remaining 12.0 cases might be induced by inhaled $\mathrm{SiO}_{2}$. The possible combined effects between $\mathrm{ThO}_{2}$ and $\mathrm{SiO}_{2}$ in such a mine could be negligible (Spiethoff et al., 1994). 
In 1979, Panomareva found the enhancing effect between dust, $\mathrm{ThO}_{2}$ and chronic $\gamma$ exposure (Panomareva, 1979).

Therefore the excess lung cancer deaths of the exposed miners in mining workshop, the combined effect of chronic $\gamma$ exposure and the inhaled thorium dusts could not be excluded.

\subsection{Estimated thorium lung burdens and relationship to hematological and hepatic parameters of the dust-exposed miners (Chen and Cheng, 1989)}

During the period 1983-1994, 1158 measurements of the four hematological parameters (haemoglobin, white blood cells, neutrophils and lymphocytes) and four hepatic parameters (thymol turbidity test, glutamic pyruvic transaminase, thymol flocculation test and alkaline phosphatase) were performed on 638 dustexposed miners. No adverse effects were observed. None of of the above mentioned 638 exposed miners had a thorium lung burden estimate higher than $11.11 \mathrm{~Bq}$.

\subsection{Follow-up study (1983-1990) of the clearance of thorium dioxide from the lung of a miner having a high thorium lung burden (Chen et al., 1995)}

Since 1983, a seven year follow-up study has been carried out using the exhaled thoron progeny measurement system to observe the clearance of thorium dioxide from the lung of a miner before and after leaving work. The results indicate that $44 \%$ of the initial lung burden was clearing with a half time of 112 days and $56 \%$ was clearing with a half time of about 7000 years. The longer half time was attributed to the dusts being surrounded by fibrotic tissues in this miner's lung. In which, only thoron gas, but not dusts, could move away from the sites of deposition. In 1985, this subject suffered from stage 1 pneumoconiosis. His X-ray film showed an increase of veins and grains in the pulmonary area. Scattered small nodules appeared on the middle and lower lobes of the lung.

\subsection{Health protection measures and results}

The authors suggested this mine to apply the following protection measures.

(1) Devices for ventilation and prevention of dusts should be improved.

(2) Instructions for use of the individual protection appliances should be promoted. 
(3) Participation in popular sports should be encouraged. It was observed that in this mine the amount of thorium deposited in the lungs of dust-exposed miners who habitually run was generally low.

(4) Job rotation is suggested for those having an estimated thorium lung burden higher than $4.44 \mathrm{~Bq}$. These measures achieved positive results.

\section{Conclusion}

This study showed that the highest thorium lung burden of the dust-exposed miners in this mine was $11.11 \mathrm{~Bq}$. The number of cases of pneumoconiosis of stage $0^{+}$in the crushing workshop was much higher than that in the mining workshops. Epidemiological studies showed that the excess lung cancers of the dust-exposed miners have clearly appeared since 1994, that is, 36 years after the mining of this mine, although there was some prior evidence of excess lung cancers before 1994. Long-term exposure to thorium-containing dusts (carcinogens are $\mathrm{ThO}_{2}$ and $\mathrm{SiO}_{2}$ ) and to thoron progeny resulted in inducing excess lung cancers, contrary to the most recent findings from an American thorium processing plant (Liu et al., 1992). High rate of smoking among the Baiyan Obo miners (80\%) (Chen et al., 2000) and high gamma exposure in mining workshops might enhance the carcinogenic effect of inhaled thorium-containing dust and thoron progeny in inducing excess lung cancers. This is the first evidence in humans of the carcinogenicity after long-term inhalation of thorium-containing dusts and thoron progeny (IARC, 2000). The confounding factor cigarette smoking is excluded, in the above-mentioned 10 excess lung cancers.

According to our estimation, among the 27 cases of lung cancer deaths of the dust exposed miners, 1 case was induced by the inhaled thorium, 2.0 case were induced by the inhaled short-lived thoron daughters, 12 cases were induced by cigarette smoking, and the remaining 12 cases might be induced by $\mathrm{SiO}_{2}$. The possible combined effects between $\mathrm{ThO}_{2}$ and $\mathrm{SiO}_{2}$ in such a mine could be negligible. However, the combined effects of chronic $\gamma$ exposure and the inhaled thorium dusts on the miners in mining workshop in inducing lung cancer could not be excluded.

Acknowledgments. The financial support for this work from the WHO, NNSFC, IAEA (1994, 2001) is duly acknowledged. The author thanks Dr. James Stebbings for his help in improving the analysis of epidemiological data, and also the help from Dr. C. Richmond in improving the whole paper. In particular, the author wish to thank Prof. Wu De-chang and Dr. R.O. McClellan for their important comments on this paper. 


\section{REFERENCES}

Chen X.A. (2001) A Progress Report to IAEA, Chin. J. Radiol. Health 10, 231.

Chen X.A., Cheng Y.E. (1989) Long-term monitoring of thorium inhaled by workers and assessment of thorium lung burden in China, Rad. Prot. Dosim. 79, 91-93.

Chen X.A., Xiao H.J., Cheng Y.E., Yang Ying-jie (1995) An observation on the clearance of thorium dioxide from the lung of a miner, J. Radial. Prot. 15, 343-346.

Chen X.A., Cheng Y.E., Zhen R. (2000) Health effects following long-term exposure to thorium dusts, A fourteen-year follow-up study in China, In: Proceedings of the 10th International Congress of IRPA, Hiroshima, Japan Health Physics Society (CD-ROM) Hiroshima 2000.

Ginevan M.E. (1981) Poisson trials approach to interpopulation comparisons of cause of death data, Environm. Reas. 25, 147-159.

IARC (1996) Monographs on the evaluations of the carcinogenic risk of chemicals of humans, Vol. 68: Silica and Silica Compounds. CRC Press Inc.

IARC (2000) Monographs on the evaluation of carciongenic risks to humans, Vol. 78: Ionizing radiation, part 2: Some internally deposited radionuclides, p. 175. IARC Press, Lyon.

ICRP Publication 10 (1968) Evaluation of radiation doses to body tissues from internal contamination due to occupational exposure, pp. 115-120. Oxford Pergamon Press, Oxford.

ICRP Publication 10A (1975) The Assessment of internal contamination resulting from recurrent or prolonged uptakes, pp. 5-6. Oxford Pergamon Press, Oxford.

ICRP Publication 47 (1986) Radiation protection of workers in mines, Ann. ICRP 16 (1).

ICRP Publication 66 (1994) Human respiratory truct model for radiological protection, Ann. ICRP 24 (1-3).

Jarvis N.S., Birchall A., James A.C., Bailey M.R., Dorrian M.D. (1996) LUDEP 2.0 Personal Computer Program for calculating internal dose using the ICRP Publication 66 respiratory tract model, NRPB-SR287.

Li Wenyuan, Hou Qing-mei, Lu Hui-min (1988) A preliminary investigation on the AMAD values of the thorium dusts in the air of the workshops of Baiyun Obo Iron Mine, Chin. J. Rad. Med. Prot. 8, 410-413.

Liu Z., Lee T.S., Kotek T. (1992) Mortality among workers in a thorium-processing plant-A second follow-up, Scand. J. Work Environm. Health 18, 162-168.

Panomareva B.L. (1979) Long-term effect on rats of the dust radiation factor combined with chronic $\gamma$ irradiation, Industrial hygiene and professional diseases, No. 12, p. 34.

Porstendorfer J., Mercer T.T. (1979) Influence of electric charge humidity upon the diffusion coeffcient of radon decay products, Health Phys. 37, 191-199.

Spiethoff A., Wesch H., Wegener K., Klimisch H.-J. (1994) Interaction of thorotrast and quartz in the induction of lung tumors in rats. Health effects of internally deposited radionuclides: Emphasis on radium and thorium, Proceedings of an international seminar held in Heidelberg, Germany, 18-21 April 1994.

Stehney A.F., Polednak A.P., Rundo J., Brues A.M., Lucas Jr H.F., Patten B.C, Rowland R.E. (1980) Health status and body radioactivity of thorium workers. interim report, Argonne National Laboratory, Argronne, Illinois, pp. 33-34.

Xu Jinkui, Zhang Jian, Chen Xing-an (1994) An assessment of the air concentrations of radon and thoron progeny in the crushing workshop of Bayun Obo Rare-Earth Iron Mine, Chin. J. Rad. Med. Prot. 14, 185-188. 